\title{
Penentuan Prioritas Pengembangan Kawasan Transit Stasiun Gubeng dengan Konsep Transit Oriented Development
}

\author{
Virta Safitri Ramadhani dan Sardjito \\ Departemen Perencanaan Wilayah dan Kota, Fakultas Teknik Sipil dan Perencanaan, Institut \\ Teknologi Sepuluh Nopember (ITS) \\ e-mail: sardjito@urplan.its.ac.id
}

\begin{abstract}
Abstrak-Stasiun Gubeng merupakan stasiun utama di Kota Surabaya yang memiliki peranan besar dalam melayani perjalanan kereta jarak jauh di pulau Jawa dan kereta komuter Surabaya-Sidoarjo. Adanya kebijakan pengembangan Kota Surabaya, menjadikan kawasan di sekitar lokasi transit Stasiun Gubeng menjadi salah satu kawasan yang akan dikembangkan dengan konsep Transit Oriented Development (TOD). Pembangunan sarana dan prasarana yang mengarah pada komponen TOD sudah dilakukan di kawasan transit Stasiun Gubeng. Namun, pembangunan tersebut belum terintegrasi antar komponen dan belum dapat segera teruwujud untuk mengarah ke bentuk kawasan TOD. Sehingga diperlukan penentuan prioritas dalam pelaksanaan pengembangan di kawasan transit agar dapat terintegrasi dan mendukung percepatan realisasi pengembangan TOD di kawasan Stasiun Gubeng. Dari hasil penelitian yang dilakukan dapat ditentukan prioritas pengembangan dalam rangka mewujudkan kawasan transit Stasiun Gubeng dengan konsep TOD.
\end{abstract}

Kata Kunci-Kawasan transit, Prioritas pengembangan, Stasiun Gubeng, Transit Oriented Development.

\section{PENDAHULUAN}

$\mathrm{P}$ ERMASALAHAN transportasi merupakan permasalahan yang terjadi di kota-kota besar di Indonesia. Permasalahan ini meliputi terbatasnya sarana dan prasarana transportasi, urbanisasi yang cepat, rendahnya tingkat kedisiplinan dalam berlalu lintas dan lemahnya sistem perencanaan transportasi. Hal ini mengakibatkan kemacetan, polusi, kecelakaan, dan hal lain yang tidak bisa dihindari. [1]

Stasiun Gubeng merupakan stasiun utama dan terbesar di Kota Surabaya maupun Jawa Timur, yang melayani perjalanan kereta jarak jauh di pulau Jawa dan kereta komuter SurabayaSidoarjo. Terdapat rencana jalur rel double-track SurabayaJuanda-Mojokerto dan rencana pembangunan monorail di kawasan transit Stasiun Gubeng yang akan menimbulkan bangkitan besar di lokasi transit. Kawasan di sekitar lokasi transit tersebut dapat menjadi kawasan potensial dalam hal kegiatan ekonomi. Terlebih lagi dalam RTRW Kota Surabaya, kawasan di sekitar Stasiun Gubeng direncanakan menjadi kawasan kegiatan yang heterogen, khususnya untuk kegiatan perkantoran dan komersial yang tentunya akan menimbulkan bangkitan lalu lintas yang besar. [2][3]
Dalam kebijakan perencanaan Kota Surabaya, kawasan di sekitar lokasi transit Stasiun Gubeng menjadi salah satu kawasan yang dikembangkan dengan konsep TOD. Keterkaitan antara karakteristik kawasan transit terhadap jumlah pergerakan di Stasiun Gubeng, menjadikan kawasan transit Stasiun Gubeng memiliki potensi untuk dikembangkan melalui konsep TOD. Transit Oriented Development (TOD) merupakan konsep kawasan yang nyaman untuk berjalan kaki, dibentuk dari pembangunan mix use, memiliki kepadatan yang tinggi yang membuat masyarakat nyaman dalam transit dan mendorong menggunakan transportasi publik. TOD juga mendukung penggunaan moda transportasi yang berkelanjutan seperti transportasi umum, berjalan dan bersepeda, serta mengurangi jarak perjalanan yang akan mengurangi kemacetan lalu lintas. [4][5]

Di kawasan transit Stasiun Gubeng juga sudah terdapat pembangunan sarana dan prasarana yang mengarah pada komponen-komponen TOD dengan jenis kegiatan guna lahan seperti perdagangan dan jasa, perkantoran, fasilitas umum, dan pembangunan jaringan jalur pejalan kaki. Namun, pola pembangunan di sekitar kawasan transit belum terintegrasi satu sama lain antar komponen dalam mengarah ke bentuk kawasan dengan konsep TOD. Dengan pengembangan seperti itu, realisasi dalam pengembangan kawasan transit Stasiun Gubeng dengan konsep TOD belum dapat segera terwujud. Sehingga diperlukan prioritas dalam pelaksanaan pengembangan di kawasan transit dengan konsep TOD agar dapat terstruktur dan terintegrasi, baik dalam pembangunan antar komponen dan lembaga atau instansi yang nantinya akan menjalankannya.

Berdasarkan penjelasan diatas, maka diperlukan penelitian untuk mengetahui prioritas pengembangan pada kawasan transit di Surabaya, guna membentuk kawasan yang nyaman bagi pelaku pergerakan di sekitar kawasan transit Stasiun Gubeng dalam pengembangan TOD nantinya.

\section{METODE PENELITIAN}

\section{A. Metode Pengumpulan Data}

Pengumpulan data dalam penelitian ini dilakukan dengan survey primer dan survey sekunder. Survey primer dilakukan dengan cara observasi lapangan dan wawancara. Observasi lapangan dilakukan dengan menggunakan teknik purposive sampling. Sedangkan survey sekunder dilakukan dengan cara 
survey instansional dalam mendapatkan data-data yang mendukung penelitian.

\section{B. Metode Analisis Data}

Dalam menganalisis kesesuaian kawasan transit Stasiun Gubeng dengan konsep TOD dilakukan tiga tahapan analisis, yakni:

1) Mengidentifikasi kriteria-kriteria konsep TOD yang sesuai dengan kawasan transit Stasiun Gubeng

Dalam mengidentifikasi kriteria-kriteria konsep TOD yang sesuai dengan kawasan transit digunakan analisis Delphi, dengan menganalisis variabel-variabel konsep TOD yang didapatkan dari hasil kajian pustaka dengan menyatukan pendapat beberapa ahli (pemerintah, swasta dan akademisi) hingga terjadi konsensus. Terdapat dua belas variabel dalam penelitian ini, yaitu kepadatan bangunan, koefisien dasar bangunan (KDB), koefisien lantai bangunan (KLB), penggunaan lahan perumahan, penggunaan lahan perkantoran, penggunaan lahan perdagangan dan jasa, penggunaan lahan fasilitas umum, ketersediaan jalur pejalan kaki, dimensi jalur pejalan kaki, konektivitas jalur pejalan kaki, ketersediaan fasilitas penyebrangan dan ketersediaan fasilitas sepeda. Variabel-variabel diatas mewakili prinsip-prinsip TOD berupa density (kepadatan penggunaan lahan), diversity (penggunaan lahan campuran), dan design (ramah terhadap pejalan kaki). [6][7][8][9][10]

\section{2) Menganalisis kesesuaian karakteristik kawasan transit} dengan kriteria kawasan TOD

Dalam menganalisis kesesuaian karakteristik kawasan transit dengan kriteria TOD dilakukan dengan analisis kriteria. Analisis kriteria dilakukan dengan menggunakan teori yang menjadi pertimbangan dalam mengidentifikasi sejauh mana kesesuaian kondisi eksisting kawasan transit Stasiun Gubeng dengan kriteria TOD. Kriteria yang digunakan dalam analisis ini diperoleh dari hasil tinjauan pustaka pada beberapa pedoman seperti TOD standard yang dikeluarkan oleh Institute for Transportation Development and Policy, Florida TOD Guidebook, dan beberapa peraturan menteri. [8]-[10] Standar yang digunakan sebagai kriteria bersifat umum dan sudah disesuaikan dengan beberapa peraturan menteri maupun daerah, sehingga dapat diadaptasikan di Indonesia. Berikut merupakan kriteria kawasan TOD.
Tabel 1.

Kriteria Kawasan dengan Konsep TOD

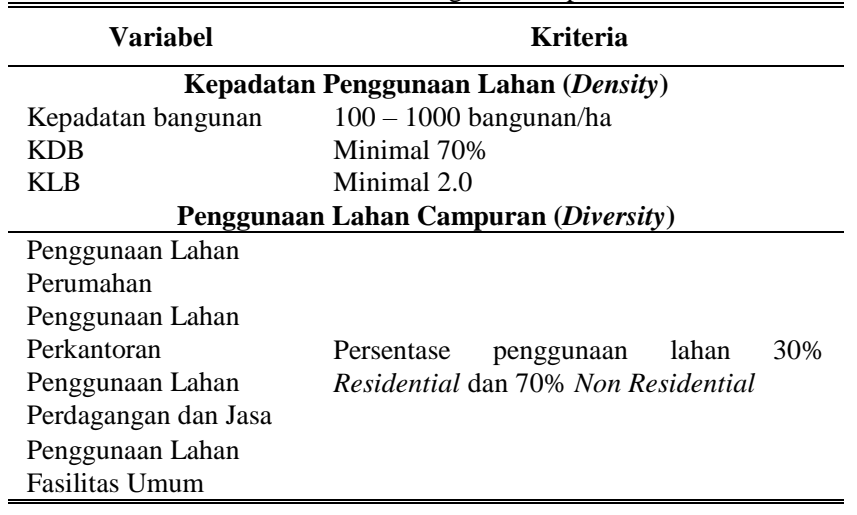

\begin{tabular}{|c|c|}
\hline Variabel & Kriteria \\
\hline \multicolumn{2}{|c|}{ Ramah Terhadap Pejalan Kaki (Design) } \\
\hline $\begin{array}{l}\text { Ketersediaan Jalur } \\
\text { Pejalan Kaki }\end{array}$ & $\begin{array}{l}\text { - Memiliki tactile pada permukaan } \\
\text { pedestrian yang mendukung difabel } \\
\text { - Tersedia pohon peneduh di sepanjang } \\
\text { jalur pejalan kaki }\end{array}$ \\
\hline $\begin{array}{l}\text { Konektivitas Jalur } \\
\text { Pejalan Kaki }\end{array}$ & $\begin{array}{l}\text { Waktu tempuh maksimal } 10 \text { menit dari dan } \\
\text { menuju lokasi transit }\end{array}$ \\
\hline $\begin{array}{l}\text { Dimensi jalur pejalan } \\
\text { kaki }\end{array}$ & Lebar minimal 2 meter \\
\hline $\begin{array}{l}\text { Ketersediaan fasilitas } \\
\text { jalur sepeda }\end{array}$ & $\begin{array}{l}\text { - Lebar jalur minimal } 1,5 \text { meter } \\
\text { - Memiliki jalur khusus yang aman dari } \\
\text { kendaraan bermotor }\end{array}$ \\
\hline $\begin{array}{l}\text { Ketersediaan fasilitas } \\
\text { penyebrangan }\end{array}$ & $\begin{array}{l}\text { Memiliki fasilitas penyebrangan berupa } \\
\text { jembatan penyebrangan, zebra cross, atau } \\
\text { penyebrangan pelikan pada tiap } \\
\text { persimpangan dan di pusat kegiatan. }\end{array}$ \\
\hline
\end{tabular}

Sumber:TOD Guidebook, 2012 dan TOD Standars, 2014

3) Menentukan prioritas pengembangan kawasan transit Stasiun Gubeng dengan konsep TOD

Penentuan prioritas pengembangan kawasan transit Stasiun Gubeng dilakukan dengan menggunakan analisis AHP (Analytical Hirerarchy Process). Hasil analisis ini didapatkan dari pendapat para ahli yang kemudian diolah menggunakan software Expert Choice 11.

\section{HASIL DAN DISKUSI}

Lingkup wilayah penelitian yang digunakan adalah kawasan Stasiun Gubeng dengan radius 700 meter. Kawasan transit ini memiliki luas 81,37 Ha yang terdiri dari tujuh blok pengembangan. Jenis penggunaan lahan di kawasan transit cukup beragam seperti perumahan, perdagangan dan jasa, perkantoran, fasilitas umum, dan RTH. Kawasan ini merupakan kawasan potensial dimana dalam RTRW Kota Surabaya akan direncanakan menjadi kawasan perkantoran dan komersial. 


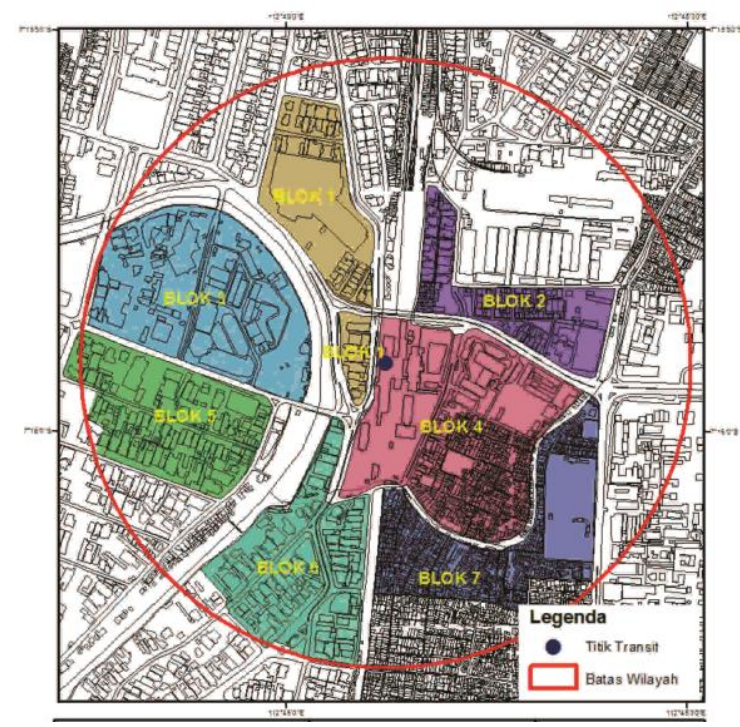

Gambar 1. Peta Lingkup Wilayah Penelitian dan Blok Pengembangan.

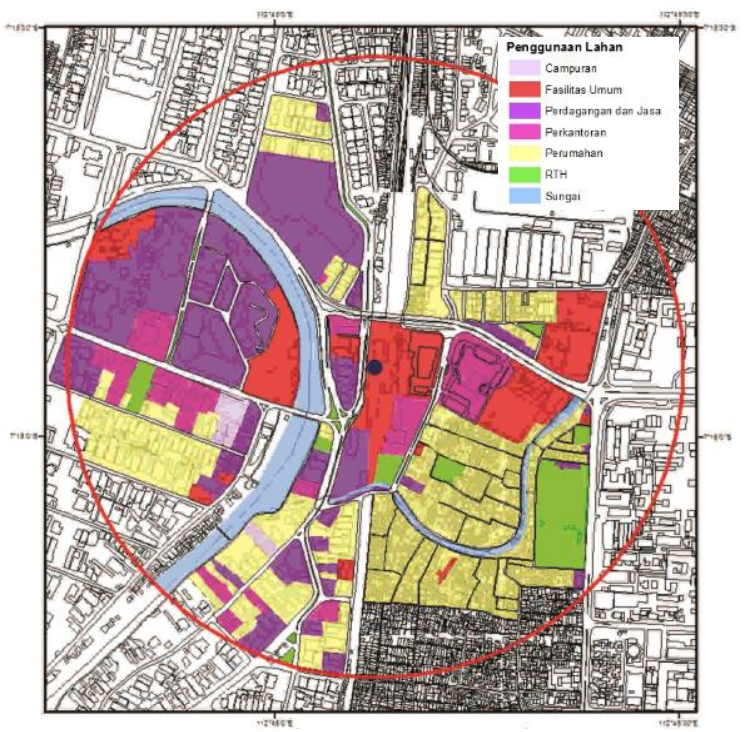

Gambar 2. Peta Penggunaan Lahan di Kawasan Transit.

Berdasarkan hasil identifikasi lapangan maupun data, pada indikator kepadatan penggunaan lahan, kepadatan bangunan di kawasan transit adalah 33 bangunan/ha yang masuk ke dalam kategori rendah. Ditinjau dari variabel KDB, kawasan transit memiliki rata-rata nilai KDB sebesar $70 \%$ dan untuk variabel KLB memiliki nilai rata-rata sebesar 3.30. Untuk indikator penggunaan lahan campuran, memiliki proporsi penggunaan lahan residential sebesar $36 \%$ dan penggunaan lahan non residential sebesar $64 \%$. Dan pada indikator ramah terhadap pejalan kaki, rata-rata dimensi jalur pejalan kaki sebesar 2,5 meter, dengan rata-rata waktu tempuh dalam mencapai lokasi transit adalah 8,5 menit.

\section{A. Identifikasi kriteria-kriteria konsep TOD yang sesuai dengan kawasan transit Stasiun Gubeng}

Berdasarkan hasil identifikasi kriteria-kriteria konsep TOD yang didapatkan dari variabel-variabel penelitian dan proses analisis, didapatkan dua belas variabel yang sesuai dengan kawasan transit Stasiun Gubeng. Variabel tersebut didapatkan dari hasil analisis Delphi dengan dua kali iterasi. Variabel- variabel tersebut adalah kepadatan bangunan, KDB, KLB, penggunaan lahan perumahan, penggunaan lahan perkantoran, penggunaan lahan perdagangan dan jasa, penggunaan lahan fasilitas umum, ketersediaan jalur pejalan kaki, dimensi jalur pejalan kaki, konektivitas jalur pejalan kaki, ketersediaan fasilitas penyebrangan dan ketersediaan fasilitas sepeda. Hasil identifikasi tersebut kemudian menjadi input bagi proses analisis selanjutnya.

\section{B. Analisis kesesuaian karakteristik kawasan transit dengan kriteria kawasan TOD}

Dalam menganalisis kesesuaian kawasan transit dengan konsep TOD, digunakan pedoman kriteria yang didapatkan dari beberapa standar TOD, sehingga dapat menunjukkan sejauh mana kondisi eksisiting kawasan transit sesuai dengan kriteria konsep TOD. Berdasarkan hasil analisis, dapat diketahui bahwa kawasan transit Stasiun Gubeng masih belum sesuai dengan kriteria kawasan TOD, terutama pada kepadatan bangunan, penggunana lahan campuran, ketersediaan jalur pejalan kaki, dan ketersediaan jalur sepeda. Adapun hasil perbandingan kesesuaian kawasan transit dengan kriteria kawasan TOD dapat dilihat pada tabel berikut. 
Tabel 2.

Kesesuaian Karakteristik TOD di Kawasan Transit Stasiun Gubeng

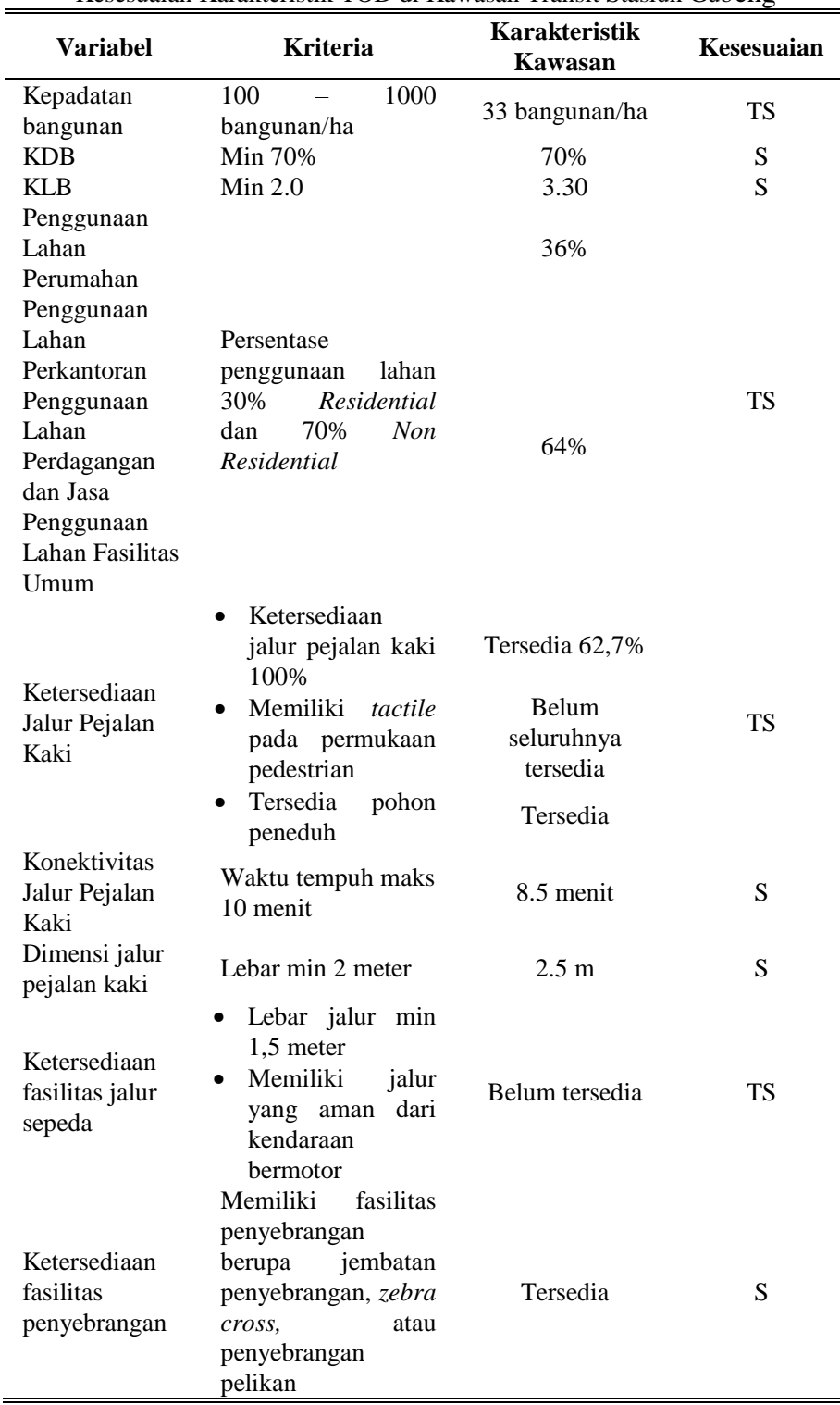

Keterangan: $\mathrm{S}=$ Sesuai, $\mathrm{TS}=$ Tidak Sesuai

Sumber: Hasil Analisis, 2017

C. Penentuan prioritas pengembangan kawasan transit Stasiun Gubeng dengan konsep TOD

Berdasarkan hasil analisis, didapatkan output penilaian bobot dalam penentuan prioritas pengembangan kawasan transit Stasiun Gubeng. Hasil output tersebut dapat dilihat sebagai berikut:

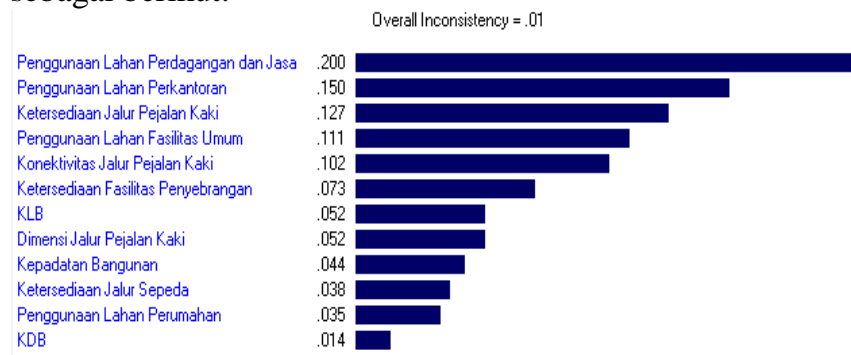

Gambar 3. Hasil Output Prioritas Pengembangan Kawasan Transit Stasiun Gubeng
Pada grafik hasil output diatas, dapat dilihat urutan bobot dari tertinggi hingga terendah dalam prioritas pengembangan kawasan transit adalah:

1. Penggunaan Lahan Perdagangan dan Jasa $=0,200$

2. Penggunaan Lahan Perkantoran $=0,150$

3. Ketersediaan Jalur Pejalan Kaki $=0,127$

4. Penggunaan Lahan Fasilitas Umum $=0,111$

5. Konektivitas Jalur Pejalan Kaki $=0,102$

6. Ketersediaan Fasilitas Penyebrangan $=0,073$

7. Koefisien Lantai Bangunan (KLB) $=0,052$

8. Dimensi Jalur Pejalan Kaki $=0,052$

9. Kepadatan Bangunan $=0,044$

10. Ketersediaan Jalur Sepeda $=0,038$

11.Penggunaan Lahan Perumahan $=0,035$

12. Koefisien Dasar Bangunan $=0,014$

Dari hasil output penilaian bobot dengan menggunakan analisis AHP, dapat disimpulkan prioritas pengembangan kawasan transit terhadap variabel TOD dijelaskan pada tabel dibawah ini.

Tabel 3.

Prioritas Pengembangan Kawasan Transit Stasiun Gubeng dengan Konsep TOD

\begin{tabular}{cl}
\hline \hline Prioritas & \multicolumn{1}{c}{ Variabel } \\
\hline $\mathbf{1}$ & Penggunaan Lahan Perdagangan dan Jasa \\
$\mathbf{2}$ & Penggunaan Lahan Perkantoran \\
$\mathbf{3}$ & Ketersediaan Jalur Pejalan Kaki \\
$\mathbf{4}$ & Penggunaan Lahan Fasilitas Umum \\
$\mathbf{5}$ & Konektivitas Jalur Pejalan Kaki \\
$\mathbf{6}$ & Ketersediaan Fasilitas Penyebrangan \\
$\mathbf{7}$ & Koefisien Lantai Bangunan (KLB) \\
$\mathbf{8}$ & Dimensi Jalur Pejalan Kaki \\
$\mathbf{9}$ & Kepadatan Bangunan \\
$\mathbf{1 0}$ & Ketersediaan Jalur Sepeda \\
$\mathbf{1 1}$ & Penggunaan Lahan Perumahan \\
$\mathbf{1 2}$ & Koefisien Dasar Bangunan (KDB) \\
\hline \hline Sumber: Hasil Analisis, 2017
\end{tabular}

Dari hasil prioritas diatas, penggunaan lahan perdagangan dan jasa (non residential) memiliki prioritas tertinggi. Penggunaan lahan campuran menjadi prinsip utama dalam pengembangan kawasan TOD. Dengan banyaknya aktivitas guna lahan di kawasan transit, akan mempengaruhi bangkitan dan tarikan, serta demand penumpang yang akan menggunakan transportasi publik di kawasan transit nantinya. Sebagai tindak lanjut dari penentuan prioritas pengembangan kawasan transit terhadap variabel TOD, dapat diberikan deskripsi pengembangan pada tiap variabel pada tabel berikut. 
Tabel 4.

Prioritas dan Deskripsi Pengembangan Kawasan Transit Stasiun Gubeng

\begin{tabular}{|c|c|c|}
\hline Prioritas & Variabel & Deskripsi Pengembangan \\
\hline 1 & $\begin{array}{l}\text { Penggunaan } \\
\text { Lahan } \\
\text { Perdagangan } \\
\text { dan Jasa }\end{array}$ & $\begin{array}{l}\text { Menambah luas penggunaan lahan non } \\
\text { residential yang khususnya dapat } \\
\text { dialokasikan untuk kegiatan perdagangan } \\
\text { dan jasa di seluruh kawasan transit. }\end{array}$ \\
\hline 2 & $\begin{array}{l}\text { Penggunaan } \\
\text { Lahan } \\
\text { Perkantoran }\end{array}$ & $\begin{array}{l}\text { Menambah luas penggunaan lahan non } \\
\text { residential khususnya dapat dialokasikan } \\
\text { untuk kegiatan perkantoran pada blok } 3,5 \text {, } \\
\text { dan } 6 \text {. }\end{array}$ \\
\hline 3 & $\begin{array}{l}\text { Ketersediaan } \\
\text { Jalur Pejalan } \\
\text { Kaki }\end{array}$ & $\begin{array}{l}\text { Meningkatkan ketersediaan jalur pejalan } \\
\text { kaki di seluruh ruas jalan di kawasan } \\
\text { transit. }\end{array}$ \\
\hline 4 & $\begin{array}{l}\text { Penggunaan } \\
\text { Lahan Fasilitas } \\
\text { Umum }\end{array}$ & $\begin{array}{l}\text { Mempertahankan area penggunaan lahan } \\
\text { fasilitas umum yang berada di kawasan } \\
\text { transit. }\end{array}$ \\
\hline 5 & $\begin{array}{l}\text { Konektivitas } \\
\text { Jalur Pejalan } \\
\text { Kaki }\end{array}$ & $\begin{array}{l}\text { Mengembangkan jalan-jalan penghubung, } \\
\text { menerapkan pola jaringan jalan grid dan } \\
\text { membangun fasilitas penyebrangan jalan } \\
\text { (JPO) pada Blok } 2 \text { dan } 7 \text {. }\end{array}$ \\
\hline 6 & $\begin{array}{l}\text { Ketersediaan } \\
\text { Fasilitas } \\
\text { Penyebrangan }\end{array}$ & $\begin{array}{l}\text { Memelihara atau melakukan pengecekan } \\
\text { secara berkala pada kondisi fasilitas } \\
\text { penyebrangan di kawasan transit. }\end{array}$ \\
\hline 7 & KLB & $\begin{array}{l}\text { Meningkatkan nilai rata-rata KLB sampai } \\
\text { min } 2.0 \text { dan pada blok } 1,4 \text { dan } 7 \text { yang } \\
\text { dibatasi dengan KKOP. }\end{array}$ \\
\hline 8 & $\begin{array}{l}\text { Dimensi Jalur } \\
\text { Pejalan Kaki }\end{array}$ & $\begin{array}{l}\text { Menambahkan lebar dimensi pada jalur } \\
\text { pejalan kaki pada blok } 4 \text { yakni Jalan } \\
\text { Gerbong. }\end{array}$ \\
\hline 9 & $\begin{array}{l}\text { Kepadatan } \\
\text { Bangunan }\end{array}$ & $\begin{array}{l}\text { Meningkatkan nilai kepadatan bangunan } \\
\text { hingga } 67 \% \text { dari kepadatan bangunan saat } \\
\text { ini di kawasan transit. }\end{array}$ \\
\hline 10 & $\begin{array}{l}\text { Ketersediaan } \\
\text { Jalur Sepeda }\end{array}$ & $\begin{array}{l}\text { Membangun sarana dan prasarana yang } \\
\text { mendukung aktivitas sepeda pada Jalan } \\
\text { Pemuda (blok } 3 \text { \& 5) dan Jalan Raya } \\
\text { Gubeng (blok 6). }\end{array}$ \\
\hline 11 & $\begin{array}{l}\text { Penggunaan } \\
\text { Lahan } \\
\text { Perumahan }\end{array}$ & $\begin{array}{l}\text { Mengurangi penggunan lahan residential } \\
\text { atau dapat dialihfungsikan ke penggunaan } \\
\text { lahan non residential sebesar, yang dapat } \\
\text { dilakukan pada blok } 1,5 \text { dan } 6 \text {. }\end{array}$ \\
\hline 12 & $\mathrm{KDB}$ & $\begin{array}{l}\text { Meningkatkan nilai rata-rata KDB sampai } \\
\text { min } 70 \% \text { disesuaikan dengan arahan } \\
\text { rencana tata ruang pada blok } 1,3,5 \text { dan } 6 .\end{array}$ \\
\hline
\end{tabular}

Sumber: Hasil Analisis, 2017

\section{KESIMPULAN}

Dalam kebijakan pengembangan Kota Surabaya, kawasan transit Stasiun Gubeng menjadi salah satu kawasan yang dikembangkan dengan konsep TOD, yang membutuhkan prioritas pengembangan bagi kawasan transit agar dapat terintegrasi dengan baik dan mempercepat realisasi pengembangan kawasan transit Gubeng dengan konsep TOD.

Hasil dari analisis kesesuaian konsep TOD di kawasan transit Stasiun Gubeng menujukkan terdapat dua belas variabel yakni kepadatan bangunan, koefisien dasar bangunan (KDB), koefisien lantai bangunan (KLB), penggunaan lahan perumahan, penggunaan lahan perkantoran, penggunaan lahan perdagangan dan jasa, penggunaan lahan fasilitas umum, ketersediaan jalur pejalan kaki, dimensi jalur pejalan kaki, konektivitas jalur pejalan kaki, ketersediaan fasilitas penyebrangan dan ketersediaan fasilitas sepeda.

Dalam mendukung pengembangan kawasan TOD di kawasan transit Stasiun Gubeng, dilakukan penentuan prioritas pengembangan. Hasil analisis menunjukan prioritas pengembangan pada kawasan transit Stasiun Gubeng dengan konsep TOD adalah: 1) penggunaan lahan perdagangan dan jasa; 2) penggunaan lahan perkantoran; 3) ketersediaan jalur pejalan kaki; 4) penggunaan lahan fasilitas umum; 5) konektivitas jalur pejalan kaki; 6) ketersediaan fasilitas penyebrangan; 7) koefisien lantai bangunan (KLB); 8) dimensi jalur pejalan kaki; 9) kepadatan bangunan; 10) ketersediaan jalur sepeda; 11) penggunaan lahan perumahan; dan 12) koefisien dasar bangunan (KDB). Hasil dari penentuan prioritas pengembangan tersebut kemudian dapat direkomendasikan deskripsi pengembangan, dengan memperhatikan kondisi eksisting di kawasan transit Stasiun Gubeng.

\section{DAFTAR PUSTAKA}

[1] O. Z. Tamin, Perencanaan dn Permodelan Transportasi. Bandung: Penerbit ITB, 2000.

[2] Bappeko Surabaya, Surabaya MRT. Surabaya, 2013.

[3] Dinas Perhubungan Provinsi Jawa Timur, Rencana Induk Perkeretaapian Provinsi Jawa Timur. 2015.

[4] K. M. Isa, M. I., \& Handayeni, "Keterkaitan Karakteristik Kawasan Transit berdasarkan Prinsip Transit Oriented Development (TOD) terhadap Tingkat Penggunaan Kereta Komuter Koridor SurabayaSidoarjo," J. Tek. POMITS, vol. 2, pp. 1-6, 203AD.

[5] Land Use Planning \& Policy, Transit Oriented development policy Guidelines. Calgary, 2005.

[6] R. Cervero, Transit Oriented Development in The United States: Experiences, Challenges, and Prospects. Washington DC: Transportation Research Board, 2004.

[7] R. Watson, D., Plattus, A., \& Shibley, Time Saver Standards for Urban Design. New York: McGrawHill, 2003.

[8] Florida Department of Transportation, Florida TOD Guidebook. Florida, USA, 2012.

[9] J. Renne, Transit Oriented Development. Routledge, 2009.

[10] Institute for Transportation Development and Policy, TOD Standard. New York: Despacio, 2014. 